\title{
TWINSPAN CLASSIFICATION OF VEGETATION FROM NORTHEAST ASPECT OF LOWER TANAWAL ABBOTTABAD, PAKISTAN
}

\author{
Adeela Bibi 1 $ه$ \\ ${ }^{1}$ Department of Botany, Hazara University Mansehra-21300, Pakistan
}

\section{ABSTRACT}

The main objective of this research study was to explore the vegetation of Lower Tanawal, Pakistan from Northeast aspect. The ordination techniques TWINSPAN, DCA and CCA were used to classify the data. TWINSPAN classified 157 plant species and 20 stands into four plant communities. Four plant communities Dodonaea-Ziziphus-Oxalis, Pinus-Olea-Micromeria, Debregessia-Mentha-Isodon, and Pinus-Punica-Isodon community were noted. This study provides first information about the vegetation of Lower Tanawal, Abbottabad Pakistan from Northeast aspect.

Received 2 November 2021

Accepted 16 December 2021

Published 31 January 2022

\section{CorrespondingAuthor}

Adeela Bibi,

adeelabibi4@gmail.com

\section{DOI}

10.29121/granthaalayah.v10.i1.2022 .4423

Funding: This research received no specific grant from any funding agency in the public, commercial, or not-for-profit sectors.

Copyright: (C) 2022 The Author(s). This is an open access article distributed under the terms of the Creative Commons Attribution License, which permits unrestricted use, distribution, and reproduction in any medium, provided the original author and source are credited.
Keywords: TWINSPAN, Northeast, Vegetation, CCA, DCA, Lower Tanawal

\section{INTRODUCTION}

In this research study for the classification of species and stands TWINSPAN techniques have been used Hill (1979). The relationship between plant species and environmental variable is determined with the help of CCA. To determine the relationship among vegetation the DCA is used (Antoine and Niklaus, 2000).

\section{Study Area}

The Lower Tanawal is located in District Abbottabad, Pakistan. The Lower Tanawal is part of the Lesser Himalayas Hussain and Illahi (1991). It is situated between the $34^{\circ} 12^{\prime} 32$ and $34^{\circ} 15^{\prime} 76$ North latitude to $73^{\circ} 09^{\prime} 39$ and $73^{\circ} 03^{\prime}$ 31 East longitudes Bibi et al. (2019).

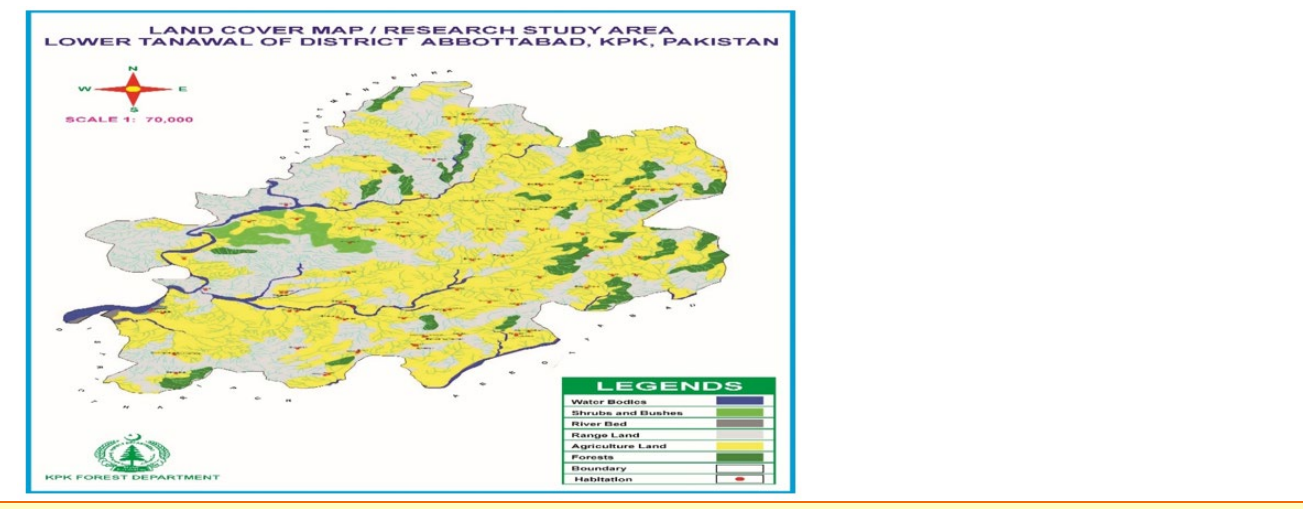

Figure 1 Location Map of Lower Tanawal Abbottabad, Pakistan 


\section{METHODOLOGY}

The vegetation analysis of Lower Tanawal from Northeast aspect was done in different seasons from 2016-2018. Line transects method was used for quantitative sampling. In this method to measure the distribution of plants measuring tape of 50 meter was used between two poles Dasti et al. (1998). During this research study 20 stands and 157 species were recognized. The IV values of 157 plants were calculated. By using MS EXCEL 2007, the data of 157 species from 20 stands along with environmental factors was analyzed (McCune, 2006). The plant community was given name on the basis of three dominant plant species. To classify plant species and samples TWINSPAN was used Hill (1979). For ordination of samples and species DCA was used Hill and Gauch (1980). CCA was used for the ordination of species, sample, and their relationships to environmental factors Braak and Barendregt (1986), Braak (1989).

\section{RESULTS}

In this classification 20 stands and 157 species were noted. The data was classified into two groups. In division 1 , thirteen stands were positioned in negative groups $\left({ }^{*} 0\right)$ whereas seven stands were positioned in positive group $(* 1)$. In division 1 the eigenvalue was 0.40 . In division 2 (13) one stand was positioned in negative group $\left({ }^{*} 00\right)$ whereas twelve stands were positioned in positive group $\left({ }^{*} 01\right)$. In division $3(12)$ five stands were positioned in negative group $\left({ }^{*} 00\right)$ whereas seven stands were positioned in positive group $(* 01)$. Then following four plant communities were formed (Figure 2).

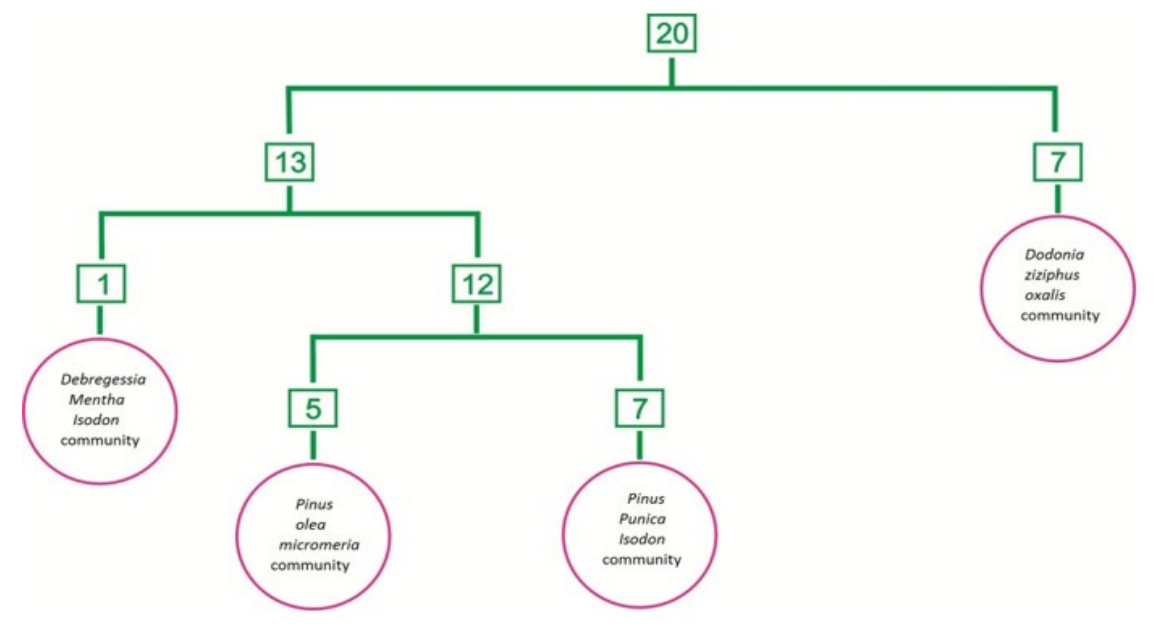

Figure 2 Twinspan Classification of Vegetation from Northeast Aspect of Lower Tanawal

During the analysis it was observed that in this community 7 stands and 105 species were recognized. This plant community was noted from the stand $19,26,20,66,23,64,51$ between the elevations of 3025-4302 ft. The diversity index was 0.76 and the species richness was 7.11 (Figure 3 ). The soil of this community was loam and pH range of the soil was 6.87 to 7.29.

\section{2) Pinus-Olea-Micromeria Community (POM)}

This community was noted from the stands 2,11, 14, 58 and 60 between the elevations of 3892 to $4843 \mathrm{ft}$. In this plant community 5 stands and 102 species 
were noted. The diversity index was 0.73 and the species richness was 7.28 (Figure 3 ). The soil was loam and pH range of the soil was 6.94 to 7.86 .

\section{3) Debregessia-Mentha-Isodon Community (DMI)}

Debregessia salicifolia, Mentha arvensis, Isodon rugosus community was recorded from stand 79, locality of Panduthana at an elevation of $4220 \mathrm{ft}$. In this community one stand and eighteen plant species were recognized. The diversity index was 0.94. The species richness was 1.97 (Figure 3). The soil of was loam and $\mathrm{pH}$ of the soil was 7.40.

\section{4) Pinus-Punica-Isodon Community (PPI)}

Pinus roxburghii, Punica granatum, Isodon rugosus community was recorded from stand 6, 41,32, 44, 54, 47, 57 between the elevations of 3560 to $4827 \mathrm{ft}$. In this community seven stands and 78 species were noted. The index of diversity was 0.84 . The species richness was 5.57 (Figure 3). The soil of this community was loam to clay loam and $\mathrm{pH}$ range of the soil was 6.80 to 7.28.

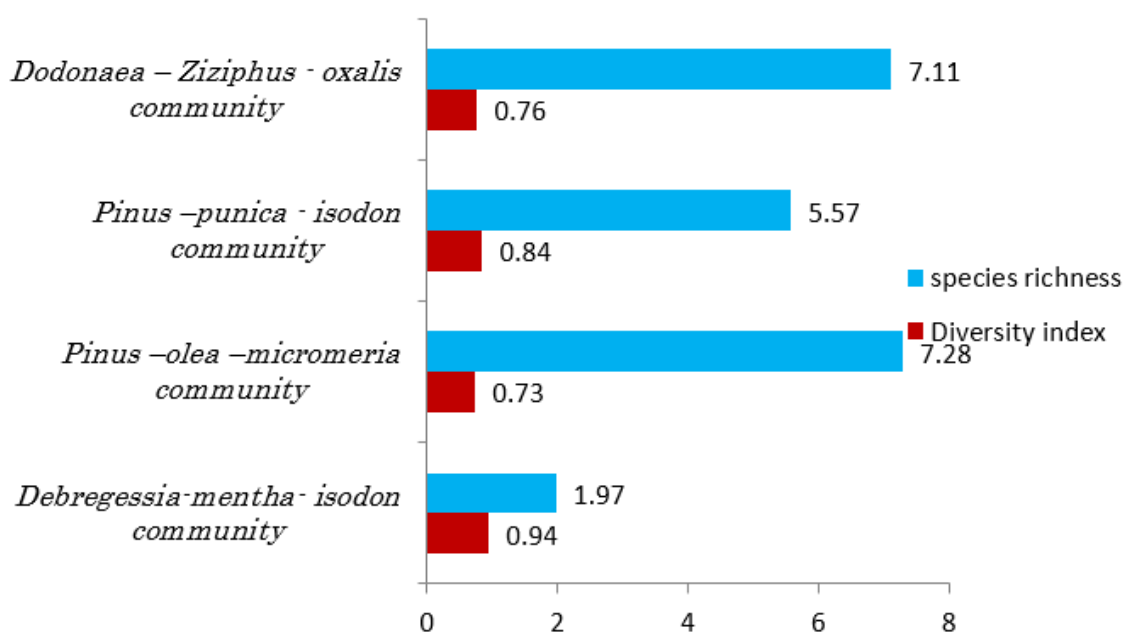

Figure 3 Diversity index and species richness of Northeast aspect

\subsection{DCA ORDINATION OF VEGETATION FROM NORTHEAST ASPECT}

In DCA ordination, for axis 2 the maximum gradient length was 3.01 having and Eigenvalue was 0.27. The gradient length at axis 1 was 2.69 with Eigenvalue 0.40. At axis 3 the gradient length was 2.13 with Eigenvalue 0.19 . The gradient length for axis 4 was 1.63 having Eigenvalue 0.12. The dominant gradient length on axis 2 indicated that maximum species has similarities on axis 2. The Eigenvalue of axes 1 and 2 shown strong correlation of species and habitat on these axes.

Cynodon dactylon, Indigofera heterantha, Indigiofera linifolia, have positive correlation with each other at axis I. Salix acmophylla, Oenotrera rosea and Isodon rugosus have positive correlation with axis 2. Berberis lycium, Pinus roxburghii, Hedera helix, Smilax china were negatively correlated with axis 1 and 2. Psidium guajava, and Eriobotrya japonica showed positive correlation on axis 1 and negative correlation with Similx china and Pinus roxburghii. Mentha arvensis and Tagetes minuta were present on the top of the ordination space and shown negative correlation with Geranium rotundifolium. Mostly species shown strong correlation and grouped together in the center. (Figure 4). 


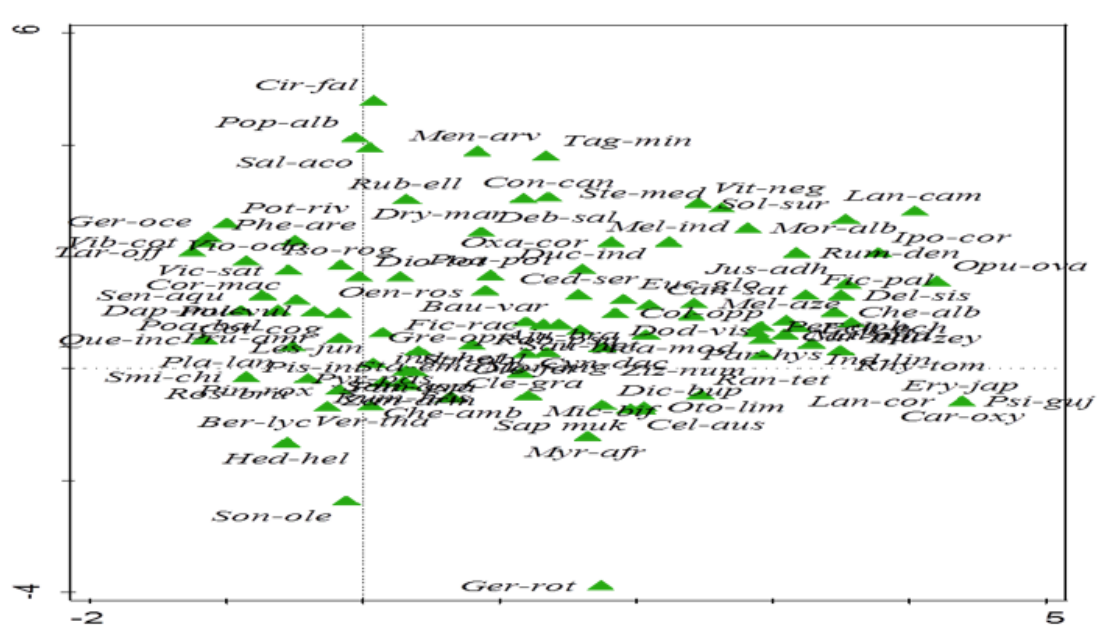

Figure 4 Northeast DCA ordination of species

DCA ordination of stands showed that stand 79 was present at the top of the ordination space and away from the others stands having diverse species and negatively correlated with stand 58 and 41 which were present on axis 1 whereas stand 2 was present on axis 2 which showed negative correlation with stand 20 whereas other stands were in the center of ordination space (Figure 5).

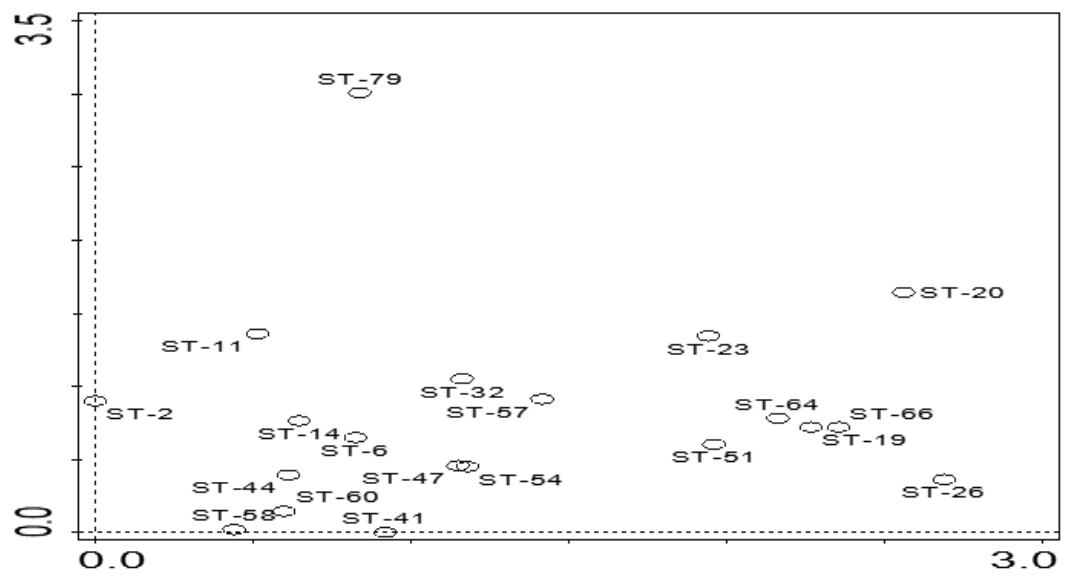

Figure 5 Northeast DCA ordination of stands

\subsection{CCA ORDINATION OF VEGETATION FROM NORTHEAST ASPECT}

The CCA ordination shown that maximum Eigenvalue was 0.39 at axis I. For axis $2(0.34)$ for axis $3(0.28)$ and for axis $4(0.25)$. The total variation was 3.45, explanatory variables account for $92.1 \%$ whereas adjusted explained variation was $24.8 \%$. The explained fitted variation for axes 1, 2, 3 and 4 were 12.27, 23.01, 32.06 and 40.12 respectively. The CCA ordination shown that Asparagus officinalis, Justicia adhatoda Indigofera heterantha, and Opuntia ovata indicated positive correlation with temperature, wet bulb, chillness, dew point, heat index and negatively correlated with slope angle.

Hedra helix, Berberis lycium, and Smilax china indicated positive correlation with phosphorus, humidity, barometer pressure, electrical conductivity, saturation, wind speed, altitude and while Oxalis corniculata, Vitis negundo, and Chenopodium 
album were negatively correlated with these factors.Gallium circaezans, and Gentiana argenta shown positive correlation with organic matter. Most species were present near average position in ordination space (Figure 6). The environmental factors dew point, chillness, temperature, and heat index have positive correlation with each other and negative correlation with slope angle and organic matter.

CCA ordination of stands showed that one stand with 14 plant species was present at the top of the ordination space. This stand has more diverse species as compared to other stands. The results of CCA ordination shown that maximum vectors strength was noted for heat index, altitude, and temperature. The intermediate vectors strength was noted for wind speed, chillness, dew point, slope angle and humidity. The less strength of vectors was documented for organic matter, saturation, slope angle, electrical conductivity, and barometer pressure (Figure 7) It was observed that from the Northeast aspect in tree maximum density was noted for Pinus roxburghii (12.6) and in shrubs maximum density was recorded for Isodon rugosus (7.4) (Figure 8).

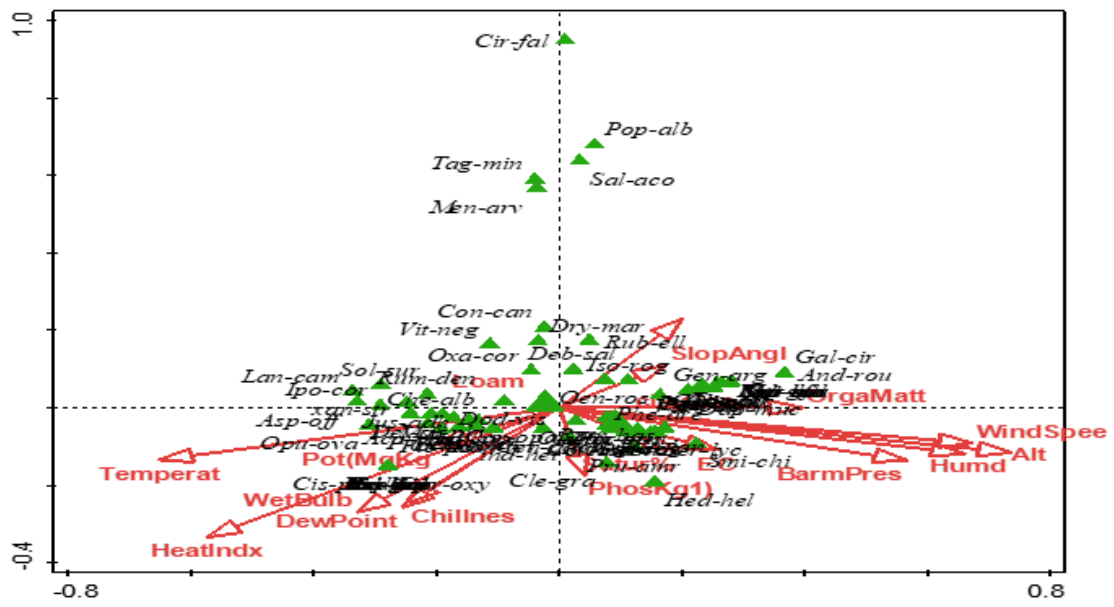

Figure 6 Northeast CCA ordination of species and environmental variable

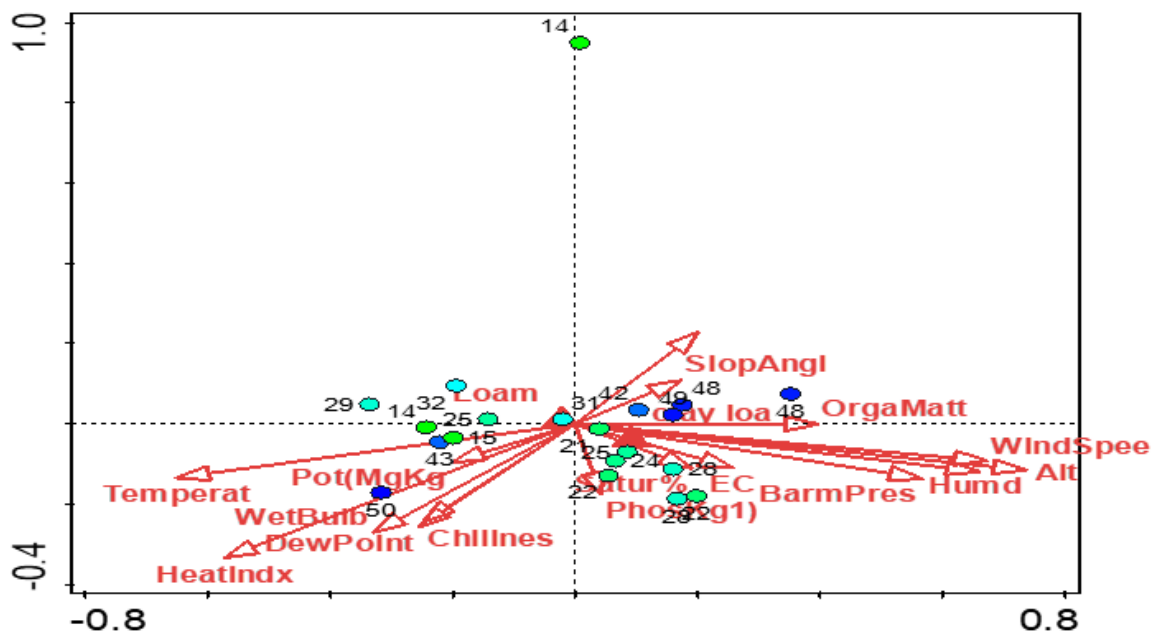

Figure 7 Northeast CCA ordination of stands and environmental Variable 


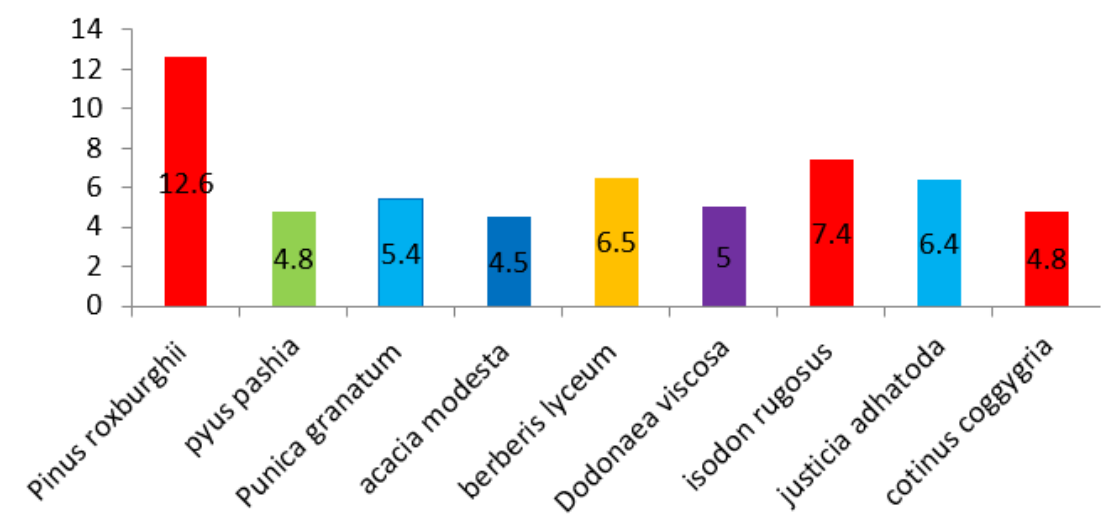

Figure 8 Density of major tree and shrubs from Northeast aspect

\section{DISCUSSION}

In DCA ordination, for axis 2 the maximum gradient length was 3.01 having and Eigenvalue was 0.27 . The dominant gradient length on axis 2 indicated that maximum species has similarities on axis 2. The results of CCA ordination shown that maximum vectors strength was noted for temperature and wind speed, which indicated that these, were most influential variable in this aspect. There was less strength of vectors for phosphorus, slope angle, potassium, and organic matter.

Phosphorus, humidity, barometer pressure, electrical conductivity, saturation, wind speed, altitude showed positive correlation with each other. Dew point, chillness, temperature, and heat index have positive correlation with each other and negative correlation with slope angle and organic matter. Most species were present near average position in ordination space. It was observed that from the Northeast aspect in tree maximum density was noted for Pinus roxburghii (12.6) and in shrubs maximum density was recorded for Isodon rugosus (7.4). It was also noted that maximum species richness (7.28) was recorded from Pinus-Olea-Micromeria Community. Maximum diversity index was noted from Debregessia-MenthaIsodon Community.

\section{REFERENCES}

Bibi, A. Z. Iqbal, G.M. Shah. (2019). Floristic diversity, biological spectrum of Lower Tanawal, KP, Pakistan. Ukr. J. Ecol., (9) 4, 505-514. Retrieved from https://doi.org/10.15421/2019_782

Dasti.A, S.A. Malik. (1998) A transect of vegetation and soil on the indus valley scarp slope, Pakistan, Pak. Plant sci, 4(2), 73-84.

F. Hussain and I. (1991) Ilahi. Ecology and Vegetation of Lesser Himalayas Pakistan. Jadoon Printing Press Peshawar,

Farag, El. M. (2014). Floristic Composition and traditional uses of plant species at Wadi Alkuf, Al-Jabal Al-Akhder, Libya. American-Eurasian J. Agric. Environ. 14 : 685-697. Retrieved from

https://www.researchgate.net/profile/Farag-Elmokasabi2/publication/309373648_Floristic_composition_and_traditional_uses_of_ plant_species_at_Wadi_Alkuf_Al-Jabal_Al-

Akhder_Libya/links/60c5c7714585157774d2e788/Floristic-compositionand-traditional-uses-of-plant-species-at-Wadi-Alkuf-Al-Jabal-Al-Akhder-

Libya.pdf 
Hill, M.O. (1979). Twinspan : A Fortran Program For Arranging Multivariate Data In An Ordered Two-Way Table By Classifcation Of The Individuals And Attributes. Ecology And Systematics, Cornell University, Ithaca, Ny.

Hill, M.O. and H.G. Gauch. (1980). Detrended correspondence analysis: An improved ordination technique. Vegetatio., 42 : 47-58. Retrieved from https://doi.org/10.1007/BF00048870

Hussain, F. and I. Illahi. (1991). Ecology and Vegetation of Lesser Himalayan Pakistan. Botany, Department. University of Peshawar, pp. 187

Khan, S.M. (2012). Plant communities and vegetation ecosystem services in the Naran valley, Western Himalaya. (Unpublished) PhD thesis, Department of Biological sciences, University of Leicester. $271 \mathrm{pp}$.

McCune, B. (1986). PC-ORD : an integrated system for multivariate analysis of ecological data. Abstr. Bot. 10 : 221-225.

Ter Braak, C.J.F. \& Barendregt, L.G., (1986). Weighted averaging of species indicator values : Its efficiency in environmental calibration. Mathematical Biosciences. 78, 57-72. Retrieved from https://doi.org/10.1016/00255564(86)90031-3

Ter Braak, C.J.F., (1989). CANOCO - an extension of DECORANA to analyze speciesenvironment relationships. Hydrobiologia. 184, 169-170 Retrieved from https://doi.org/10.1007/BF02392953 